\title{
Patient views about polypharmacy medication review clinics run by clinical pharmacists in GP practices
}

Article

Accepted Version

Snell, R., Langran, T. and Donyai, P. (2017) Patient views about polypharmacy medication review clinics run by clinical pharmacists in GP practices. International Journal of Clinical Pharmacy, 39 (6). pp. 1162-1165. ISSN 2210-7711 doi: https://doi.org/10.1007/s11096-017-0538-z Available at https://centaur.reading.ac.uk/72366/

It is advisable to refer to the publisher's version if you intend to cite from the work. See Guidance on citing.

To link to this article DOI: http://dx.doi.org/10.1007/s11096-017-0538-z

Publisher: Springer

All outputs in CentAUR are protected by Intellectual Property Rights law, including copyright law. Copyright and IPR is retained by the creators or other copyright holders. Terms and conditions for use of this material are defined in the End User Agreement.

www.reading.ac.uk/centaur 
Central Archive at the University of Reading

Reading's research outputs online 


\section{Introduction}

2 'The prescribing of multiple medicines inappropriately, or where the intended benefit of the

3 medicines are not realised' is known as problematic polypharmacy [1]. Polypharmacy can

4 decrease medication adherence and increase the incidence of adverse drug reactions (ADRs)

5 and drug-drug interactions, resulting in falls, hospitalisations and other complications

6 especially in the elderly [2]. Medication-related problems of polypharmacy can be prevented

7 through patient-centred medication reviews [1]. There is some evidence that pharmacist-led

8 polypharmacy services for older people reduce inappropriate prescribing internationally [3].

9 However, there is a perception that the majority of research in this area has been completed without examining patients' viewpoints [1]. One qualitative study conducted with patients to gather views about pharmacist-run medication review clinics in general practice found wideranging views that were themed by the authors according to patient perceptions before the reviews and then their experiences of attending [4].

Patient involvement in decisions about medication use is fundamental in polypharmacy. For example, there is conflicting evidence on patients' willingness to accept prescriber decisions to de-prescribe [5] and doctors worry about patients' unwillingness to stop longstanding medications [6]. Patient feedback about polypharmacy medication reviews is arguably a key indicator of the success of such services. Alongside this, the NHS in England has been working with the Royal Pharmaceutical Society (RPS) on a three-year pilot to test the role of clinical pharmacists within General Practice (GP) surgeries [7]. There is a gap in the literature in relation to outcomes associated with pharmacist-led medication reviews conducted within GP practices in England, specifically patients' perception of such services. 


\section{Aim of the study}

\section{Ethics approval}

\section{Methods}

The aim of this study was to investigate patient views about a patient-centred clinical pharmacist-led polypharmacy medication review service completed within GP practices with those $\geq 75$ years of age and prescribed $\geq 15$ medications.

Ethical approval was granted by the University's Research Ethics procedures (School of Food, Chemistry and Pharmacy Ethics Review Committee) in January 2016.

\section{The patient-centred pharmacist-led polypharmacy medication review service}

There were 819 patients ( $0.39 \%$ to $2.99 \%$ of patients registered with each practice) who were $\geq 75$ years of age and prescribed $\geq 15$ medications (excluding palliative care cases and those in registered care homes) in the 34 GP practices in Windsor, Ascot \& Maidenhead (in south east England); more than half (56\%) were female. The highest percentage of patients taking $\geq 15$ medicines was in the 70-79 year old age band (28\%). All 819 patients were invited via a letter to a pharmacist-led medication review at $17 \mathrm{GP}$ practices in Windsor, Ascot \& Maidenhead between April 2015 and March 2016.

Reviews were completed by one of four pharmacist independent prescribers employed by Clinical Commissioning Groups (CCGs) as prescribing support clinical pharmacists. The reviews drew on the principles of patient-centred care, medicines optimisation in polypharmacy [1], and other good-practice guidelines [8] with direct access to the medical record and in discussion with the patient. Medication changes were enacted directly on electronic systems by the pharmacist independent prescribers. The main intervention element 
was prescription changes as well as patient education and signposting. A record of all changes and recommendations, reasons for changes and projected annual cost savings were made contemporaneously and are described below.

A total of 415 consultations (with 415 different patients) were completed (51\% attendance rate) in 17 GP practices, resulting in a total of 901 medication-related changes. The changes involved stopping a medication, adding a medication, decreasing a dose, and increasing a dose. The reasons for changes were documented and categorised as relating to prescribing quality (improving clinical management or preventing harm from the medication), patient reported side-effects and formulary recommendations. Some example and reasons for common changes made included stopping an anticholinergic to reduce the risk of adverse drug reactions; starting medication for prevention of osteoporotic fractures; adjusting the dose or time of furosemide to reduce adverse drug reactions; up titration of ACE inhibitor dose in heart failure to reduce morbidity. Pharmacists also signposted patients to other services such as a falls clinic or talking therapies. A net saving of around $£ 37,000$ per annum ( $£ 90$ / patient) was predicted based on the prescribing changes, with $-£ 46,000$ as cost savings and $+£ 9,000$ as additional spends on medication.

\section{Data collection and analysis}

A patient feedback questionnaire was constructed and face validated with two pharmacists then posted by a CCG pharmacist to all patients who had taken part in the service within three months of attending. CCGs are clinically-led health bodies responsible for the planning and commissioning of health care services for local areas in England. There are 209 CCGs in England and this study covered three CCGs. Data from returned questionnaires were transferred to SPSS (v21) and analysed using descriptive statistics. Qualitative patient comments were analysed using thematic analysis meaning data were examined, coded, and themed for important ideas that related to the research question [9]. 
Results

\section{Patient views}

Completed questionnaires were returned by 166 patients resulting in a $40 \%$ response rate.

The majority ( $\mathrm{n}=138 ; 83 \%)$ found the service helpful, $21(13 \%)$ did not, $4(2 \%)$ did not know and $3(2 \%)$ did not respond. The concerns of $50(94 \%)$ of the 53 people who indicated they had a concern about their medications before their appointment were addressed, but for 2 (4\%) these were not and $1(2 \%)$ did not know. Overall $132(80 \%)$ indicated that they understood their medicines better since the pharmacist review, $21(13 \%)$ did not, $8(5 \%)$ did not know and $5(3 \%)$ did not respond. Finally, $138(83 \%)$ people were likely or extremely likely to recommend the GP surgery to friends and family if they needed similar care or treatment; $8(5 \%)$ were neither likely nor unlikely, $9(5 \%)$ were unlikely or extremely unlikely and $11(7 \%)$ were unsure. Table 1 outlines the main themes derived from analysis of qualitative responses. A small number of negative comments stated the service was not useful especially for non-English speaking patients and for those with impaired cognition.

\section{Discussion}

The feedback received from patients about the patient-centred pharmacist-led polypharmacy medication reviews indicated that the majority found these helpful, most understood their medicines better since the review, and almost all who had concerns about their medication beforehand felt these were addressed. Qualitatively, patients appreciated pharmacists' personal approach, advice and explanation, listening skills and ability to address their concerns; patients expressed satisfaction with the service and some felt it increased their confidence and knowledge of their medication.

The strengths of this study are that it reports on an area of activity where there is a distinct lack of published research. It reports on patient views about medication reviews completed by 
94 pharmacists working within GP practices. Patients were broadly happy with the service and seeing that the service in the main involved changes being made to patient prescriptions, the paper supports the idea that pharmacist-led prescribing decisions, including de-prescribing decisions, are acceptable to patients. This is important because patients' willingness to accept prescribing decisions is key to the long-term success of medication reviews.

The patient feedback questionnaire was validated with two pharmacists only. In addition, only $51 \%$ of those invited actually attended a review and of these only $40 \%$ returned a completed patient feedback questionnaire. Therefore there is a cohort of patients not represented by this study. In addition, this study did not measure views in the longer term. The Department of Health in England is proposing to restructure the provision of community pharmacy services with a focus on clinical services that are better integrated with primary care [10]. Studies such as the current one add to the evidence base to support a shift towards the employment of clinical pharmacists within GP practices, at least as far as short-term patient views are concerned. Future research should examine the longer-term effects of pharmacist interventions on health outcomes such as hospital admissions.

\section{Conclusion}

The majority of patients who participated in a patient-centred pharmacist-led polypharmacy medication review service within GP practices in Windsor, Ascot \& Maidenhead, which had resulted in numerous changes to patients' medication, expressed positive views about the service. Further research is needed to investigate clinical outcomes associated with such reviews. 


\section{Acknowledgements}

116 We would like to thank the following colleagues for contributing to the clinics: Dawn Best,

117 Melody Chapman, and Sally Clarke, all CCG Prescribing Support Pharmacists all based at

118 Windsor, Ascot \& Maidenhead CCG.

119 Funding

120 None.

\section{Conflicts of interest}

122 The authors declare that they have no conflict of interest. 


\section{References}

125 1. Duerden M, Avery T, Payne R. Polypharmacy and medicines optimisation Making it safe and sound. Kings Fund [Internet]. 2013 [cited 2017 Aug 17];1-68. Available from: https://www.kingsfund.org.uk/publications/polypharmacy-and-medicinesoptimisation

2. Maher RL, Hanlon J, Hajjar ER. Clinical consequences of polypharmacy in elderly. Expert Opin Drug Saf [Internet]. 2014 Jan [cited 2017 Aug 17];13(1):57-65. Available from: http://www.ncbi.nlm.nih.gov/pubmed/24073682

3. Patterson SM, Cadogan CA, Kerse N, Cardwell CR, Bradley MC, Ryan C, et al. Interventions to improve the appropriate use of polypharmacy for older people. Patterson SM, editor. Cochrane database Syst Rev [Internet]. 2014 May 16 [cited 2017 Aug 17];10(5):CD008165. Available from: http://www.ncbi.nlm.nih.gov/pubmed/22592727

4. Petty DR, Knapp P, Raynor DK, House AO. Patients' views of a pharmacist-run medication review clinic in general practice. Br J Gen Pract [Internet]. 2003 Aug [cited 2017 Aug 17];53(493):607-13. Available from: http://www.ncbi.nlm.nih.gov/pubmed/14601336

5. Reeve E, Wiese MD, Hendrix I, Roberts MS, Shakib S. People's attitudes, beliefs, and experiences regarding polypharmacy and willingness to deprescribe. J Am Geriatr Soc [Internet]. 2013 Sep [cited 2017 Aug 17];61(9):1508-14. Available from: http://www.ncbi.nlm.nih.gov/pubmed/24028356

6. Anthierens S, Tansens A, Petrovic M, Christiaens T. Qualitative insights into general practitioners views on polypharmacy. BMC Fam Pract [Internet]. 2010 Dec 15 [cited 
2017 Aug 17];65(11):1-6. Available from: http://www.ncbi.nlm.nih.gov/pubmed/20840795

7. NHS England. Clinical Pharmacists in General Practice Pilot. 2015 [cited 2017 Aug 17]; Available from: https://www.england.nhs.uk/gp/gpfv/workforce/building-thegeneral-practice-workforce/cp-gp/\#

8. PrescQIPPP. Polypharmacy \& Deprescribing Webkit [Internet]. 2017 [cited 2017 Aug 17]. Available from: https://www.prescqipp.info/polypharmacy-deprescribing-webkit

9. Braun V, Clarke V. Using thematic analysis in psychology. Qual Res Psychol [Internet]. 2006 Jan [cited 2017 Aug 17];3(2):77-101. Available from: http://www.tandfonline.com/doi/abs/10.1191/1478088706qp063oa

10. Cavendish W, Ridge K. Comunity pharmacy in 2016/17 and beyond [Internet]. Vol. 165, PSNC letter. 2015 [cited 2017 Aug 17]. Available from: https://www.gov.uk/government/uploads/system/uploads/attachment_data/file/486941/ letter-psnc.pdf 
Table 1. Themes derived from patient comments about the pharmacist-led polypharmacy medication reviews

\begin{tabular}{|c|c|}
\hline Main theme and sub-themes & Examples \\
\hline Process & \\
\hline $\begin{array}{l}\text { The pharmacist's personal } \\
\text { approach }\end{array}$ & “Found someone kind that cares about me." (P133) \\
\hline Being listened to & $\begin{array}{l}\text { "Made me feel as if they were listening to my } \\
\text { concerns about my medications." (P115) } \\
\text { "Had time to talk and didn't rush me at all." (P112) }\end{array}$ \\
\hline $\begin{array}{l}\text { The pharmacist's advice and } \\
\text { explanations }\end{array}$ & $\begin{array}{l}\text { "Thank you [pharmacists name] for your clear and } \\
\text { concise explanation of my medication." (P144) } \\
\text { "The pharmacist explained everything properly and I } \\
\text { felt they understood me." (P66) }\end{array}$ \\
\hline $\begin{array}{l}\text { Questions or concerns being } \\
\text { answered }\end{array}$ & $\begin{array}{l}\text { "This review I found very helpful and all my } \\
\text { questions were answered more than adequately." } \\
(P 1) \\
\text { "I thought there were perhaps some side effects from } \\
\text { my medication that I currently take, so good } \\
\text { discussion." (P107) }\end{array}$ \\
\hline
\end{tabular}

\section{Outcome}

$\begin{array}{ll}\text { Increased confidence or } & \text { "More confident getting medicines right." (P4) } \\ \text { knowledge about medication } & \text { "Elderly people tend to take their meds not really } \\ & \text { knowing what it is for and how it works. I personally } \\ & \text { learnt quite a bit by seeing the pharmacist. Overall } \\ & \text { experience was very valuable for me." (P30) } \\ \text { "Feels privileged to have had this appointment." } & (P 122) \\ \text { General satisfaction with the } & \text { "Enlightenment. This service is tantamount to a } \\ & \text { second opinion', very helpful and puts your mind to } \\ & \text { rest." (P18) }\end{array}$

